\title{
Iron deficiency and biomarkers of inflammation: a 3-year prospective analysis of the DO-HEALTH trial
}

\author{
Maud Wieczorek $^{1,2} \cdot$ Franziska Schwarz ${ }^{1,2}$. Angélique Sadlon ${ }^{1,2,3} \cdot$ Lauren A. Abderhalden $^{1,2}$. \\ Caroline de Godoi Rezende Costa Molino ${ }^{1,2}$. Donat R. Spahn ${ }^{4}$. Dominik J. Schaer ${ }^{5} \cdot$ E. John Orav ${ }^{6} \cdot$ Andreas Egli $^{1,2}$. \\ Heike A. Bischoff-Ferrari ${ }^{1,2,7}$ (D) DO-HEALTH Research group
}

Received: 3 June 2021 / Accepted: 3 August 2021 / Published online: 17 September 2021

(c) The Author(s) 2021

\begin{abstract}
Background The longitudinal association between iron deficiency and inflammatory biomarkers levels has not been fully explored among relatively healthy older adults.

Aims To assess whether iron deficiency at baseline and at any yearly follow-up time point, with or without anemia, was associated with changes from baseline in high-sensitivity C-reactive protein (hs-CRP) and interleukin-6 (IL-6) levels over 3 years. Methods This is a post-hoc observational analysis of DO-HEALTH, a double-blind, randomized controlled trial including 2157 European community-dwelling adults age 70+. The outcomes were changes from baseline in hs-CRP and IL-6 levels, measured at 12, 24, and 36 months of follow-up. Iron deficiency was defined by soluble transferrin receptor levels $>28.1 \mathrm{nmol} / \mathrm{L}$ and baseline anemia by hemoglobin levels $<130 \mathrm{~g} / \mathrm{L}$ for men and $<120 \mathrm{~g} / \mathrm{L}$ for women.

Results In total, 2141 participants were included in the analyses (mean age: 74.9 years, $61.5 \%$ of women, $26.8 \%$ with iron deficiency). Baseline iron deficiency was associated with greater increase in IL-6 levels (mean difference in change: $0.52 \mathrm{ng} / \mathrm{L}, 95 \% \mathrm{CI} 0.03-1.00, P=.04)$ over 3 years. Iron deficiency at any yearly time point was associated with higher increases in hs-CRP (mean difference in change: $1.62 \mathrm{mg} / \mathrm{L}, 95 \% \mathrm{CI} 0.98-2.26, P<.001$ ) and IL-6 levels (mean difference in change: $1.33 \mathrm{ng} / \mathrm{L}, 95 \% \mathrm{CI} 0.87-1.79, P<.001$ ) over 3 years. No significant interaction between iron deficiency and anemia was found, suggesting that the results are independent of the anemic status.

Conclusions These findings suggest that iron deficiency may play a role in low-grade chronic inflammation among relatively healthy older adults.
\end{abstract}

Keywords Iron deficiency $\cdot$ Anemia $\cdot$ Hs-CRP $\cdot$ IL-6 $\cdot$ Inflammaging $\cdot$ DO-HEALTH

Maud Wieczorek and Franziska Schwarz have contributed equally to this work

Heike A. Bischoff-Ferrari

Heike.Bischoff@usz.ch

1 Department of Aging Medicine and Aging Research, University Hospital Zurich and University of Zurich, Raemistrasse 101, 8091 Zurich, Switzerland

2 Centre on Aging and Mobility, University Hospital Zurich and City Hospital Zurich, Waid, Zurich, Switzerland

3 Ageing Epidemiology (AGE) Research Unit, Imperial College London, London, UK

\section{Introduction}

Iron deficiency (ID) is the most frequent nutritional disorder worldwide affecting populations of all ages, sexes, and ethnic descent. [1-3] Iron is an essential micronutrient and its homeostasis plays an important role in several physiological

4 Institute of Anesthesiology, University Hospital Zurich and University of Zurich, Zurich, Switzerland

5 Division of Internal Medicine, University Hospital Zurich and University of Zurich, Zurich, Switzerland

6 Department of Biostatistics, Harvard School of Public Health, Boston, USA

7 University Clinic for Aging Medicine, City Hospital Zurich, Waid, Zurich, Switzerland 
human processes, including cellular activities, erythropoiesis, and innate immune function. [4] Inflammatory stimuli induce macrophage production of interleukin-6 (IL-6), which stimulates hepatocytes to produce acute-phase proteins including C-reactive protein (CRP) [5, 6] and hepcidin. [7] This inflammation state may lead to extended hypoferremia and cause anemia. [8]

While there is good scientific evidence that inflammation may predict ID, evidence on the influence of ID on pre-existing low-grade inflammation remains limited. With aging, loss of homeostasis alters the production of cytokines, leading to a low-grade chronic systemic pro-inflammatory state characterized by permanently elevated levels of IL- 6 and CRP. This state, also called "inflammaging" [9], is considered to be a promotor of accelerated aging [10], age-related syndromes such as frailty [11-14], and mortality [15-18] in older adults. Thus, capturing iron status among older adults may be relevant to the promotion of healthy aging and the prevention of age-related chronic diseases.

Recently, high prevalence of ID was reported in a population of community-dwelling older adults. [19] To our knowledge, so far, no longitudinal prospective study has investigated the association between ID and low-grade chronic inflammation in relatively healthy older individuals. In a recent cross-sectional study, iron-deficient women with mean age 58 years showed increased levels of CRP and IL-6 compared to healthy controls. [20] However, the use of a different ID definition prevents the accurate comparison of results between studies. [21, 22]

Therefore, the aim of the present study was to assess whether the presence of ID at baseline and at yearly follow-up visits, with or without anemia, was associated with changes from baseline in high-sensitivity CRP (hs-CRP) and IL-6 levels over 3 years in a large European cohort of relatively healthy community-dwelling older adults.

\section{Methods}

\section{Study design and participants}

The study is a post-hoc observational analysis of the DOHEALTH clinical trial with a prospective, longitudinal approach. DO-HEALTH is a multi-center, double-blind, randomized controlled clinical trial designed to support healthy aging in European older adults (NCT01745263). The trial examined the individual and combined effects of omega-3 fatty acids, vitamin $\mathrm{D}$, and a simple home exercise program over 3 years of follow-up. A total of 2157 community-dwelling healthy and pre-frail seniors aged 70 years and older were recruited from 7 centers in 5 European countries: Zurich, Basel, Geneva (Switzerland), Berlin (Germany),
Innsbruck (Austria), Toulouse (France), and Coimbra (Portugal). Inclusion criteria were absence of major health events in the 5 years prior to enrollment, sufficient mobility, and good cognitive status. Further details are provided elsewhere. [23]

\section{Primary outcomes: biomarkers of inflammation}

For the present study, the 3-year-follow-up data were used. Fasting blood samples, collected in the morning were taken at baseline, 12, 24, and 36 months of follow-up. Hs-CRP levels were measured with the C-Reactive Protein Gen. 3 test on a cobas e 701 analyser (Roche) using an Immunoturbidimetric assay. IL-6 levels were measured using the Elecsys IL-6 assay on cobas e 801 analyser (Roche) with ElektroChemiLumineszenz-ImmunoAssay "ECLIA" technology. Higher levels of hs-CRP and IL-6 indicate greater inflammation.

\section{Exposures: ID and anemia}

We used soluble transferrin receptor levels (sTfR) levels as a clinical marker of ID at baseline and over the follow-up, since this parameter is not influenced by inflammation. [24] The threshold of more than $28.1 \mathrm{nmol} / \mathrm{L}$ was used to define ID as it was validated in older adults. [25-27] sTfR levels were measured with Tina-quant Transferrin ver. 2 Test on a cobas c 502 analyser (Roche) using an Immunoturbidimetric assay. Considering the lack of consensus in the definitions of ID [7], we performed sensitivity analyses using serum ferritin levels and the sTfR-ferritin index (sTfR / log Ferritin) as alternate definitions of ID. Ferritin concentrations were measured with Elecsys Ferritin Test on a cobas e 801 analyser (Roche) using ElektroChemiLumineszenz-ImmunoAssay "ECLIA" technology. ID was then defined using the established cutoffs of ferritin less than $45 \mu \mathrm{g} / \mathrm{L}[28,29]$ and $30 \mu \mathrm{g} / \mathrm{L}$ for older adults [30,31]; and of sTfR-ferritin index over $1.5 \mathrm{ng} / \mathrm{mL}$. [26, 32]

Hemoglobin was measured in the whole blood at baseline. We used hemoglobin levels less than $130 \mathrm{~g} / \mathrm{L}$ for men and less than $120 \mathrm{~g} / \mathrm{L}$ for women to define anemia, according to the World Health Organization guidelines. [33]

\section{Baseline covariates}

Participants' characteristics such as age, sex, tobacco consumption, and body mass index (BMI) were collected at baseline. Alcohol consumption (g/day) was derived from the Food Frequency Questionnaire. [34] Comorbidities were assessed with the self-administered comorbidity questionnaire. [35] Frailty status was determined 
according to Fried criteria. [36] Polypharmacy was defined as the use of 5 or more medications. Frequency of physical activity $(0,1-2, \geq 3$ times per week) was measured using the Nurses' Health Study questionnaire. [37]

\section{Statistical analysis}

Baseline demographic and clinical characteristics, including baseline hs-CRP and IL-6 levels, were compared between ID and non-ID participants using Chi-square and $t$ tests. Linear regression models based on generalized estimating equations (GEE) for repeated measurements were used to compare changes from baseline in hsCRP and IL-6 levels in participants who were ID versus non-ID at baseline. Each participant had up to 3 outcome measures (hs-CRP or IL- 6 changes from baseline at 1, 2 , and 3 years) and the primary predictors were baseline ID status, follow-up year, and the interactions between these two predictors. Models were adjusted for treatment allocation, study site and baseline covariates: age [38], sex [39], number of comorbidities [22], alcohol consumption [40], tobacco consumption [41], polypharmacy [22], frailty status [11, 13], frequency of physical activity [5], and the baseline level of the outcome. Time-varying BMI [5] and the incidence rate of infections [42] (number of infections per year/person-days per year) in the year preceding the measurement of the inflammatory biomarkers were also used as adjustment variables. These models allowed us to estimate, at each yearly follow-up, whether the change from baseline in hs-CRP or IL-6 level was different between participants who were ID compared to non-ID. Additionally, we estimated the effect of baseline ID status on hs-CRP and IL- 6 changes across all follow-up times simultaneously. Finally, to explore the effect of the presence of ID at each follow-up (rather than at baseline), we included a time-varying variable for iron status in separate, analogous GEE models controlling for baseline iron status. Mean differences in changes (MD) with $95 \%$ confidence intervals (CI) are presented.

In exploratory analyses, for each outcome, interactions between ID and age (70-74 years, 75 years and older), sex, and anemic status were tested. A sensitivity analysis was performed to investigate the association between recurrent iron deficiency (defined as sTfR levels $>28.1 \mathrm{nmol} / \mathrm{L}$ at 2 or more consecutive time points vs 1 time point—including baseline) and biomarkers levels. Furthermore, since liver and kidneys perform a major role in iron homeostasis [43-46], we excluded participants who reported baseline liver disease $(n=37)$, kidney disease $(n=54)$, and participants with incident invasive cancer over the follow-up $(n=74)$ in a second sensitivity analysis.
Statistical analyses involved using SAS version 9.4 (SAS Institute, Cary, NC). Two-sided $p$ values $<0.05$ were considered statistically significant.

\section{Results}

\section{Baseline characteristics of the study population}

Of the 2157 trial participants, $16(0.7 \%)$ had missing baseline sTfR levels. In total, 2141 participants were included in the analyses. At baseline, 573 (26.8\%) of them suffered from ID, and over the 3-year follow-up, a total of 262 new cases of ID were identified among non-ID participants at baseline. Baseline characteristics of subjects are presented in Table 1. Overall, the mean age was 74.9 (4.5) years, including 1317 (61.5\%) women. The mean levels of hsCRP and IL-6 were $2.9 \mathrm{mg} / \mathrm{L}$ (5.6) and $3.8 \mathrm{ng} / \mathrm{L}$ (6.9), respectively. At baseline, ID participants were more likely to be older $(P<0.001)$, less physically active $(P=0.009)$, at least pre-frail $(P=0.007)$, subject to polypharmacy $(P<0.001)$, and anemic $(P<0.001)$. In addition, they were more likely to have fewer years of education $(P<0.001)$, a higher BMI $(P<0.001)$, lower alcohol consumption $(P=0.008)$, and more comorbidities $(P<0.001)$, compared to the non-ID participants.

\section{Association between baseline ID and inflammatory biomarkers}

Overall, a significant difference in baseline hs-CRP levels was observed according to the iron status, with higher levels in ID subjects (unadjusted MD: $1.49 \mathrm{mg} / \mathrm{L}, 95 \% \mathrm{CI}$ : $0.78-2.21, P<0.001$ ) (Table 2). However, there was no statistically significant difference in hs-CRP levels over time between participants with ID and non-ID at baseline (Fig. 1a).

Significantly higher baseline IL-6 levels were observed in ID participants compared to non-ID participants (unadjusted MD: $1.26 \mathrm{ng} / \mathrm{L}, 95 \% \mathrm{CI}: 0.45-2.07, P=0.003)$. Over time, we found a significant increase in IL-6 levels among both non-ID $(0.52 \mathrm{ng} / \mathrm{L})$ and ID participants $(1.04 \mathrm{ng} / \mathrm{L})$, with a significantly greater increase in the latter (MD: $0.52 \mathrm{ng} / \mathrm{L}, 95 \% \mathrm{CI}: 0.03-1.00, P=0.04$ ) (Fig. 1b).

The interaction between ID and baseline anemic status was not statistically significant in hs-CRP $(P=0.23)$ and IL-6 models $(P=0.42)$, suggesting that results are independent of anemic status. A significant interaction between sex and baseline ID was found $(P=0.03)$. We observed a significant decrease in CRP levels between 
Table. 1 Baseline characteristics of the study population

\begin{tabular}{|c|c|c|c|c|}
\hline & $\begin{array}{l}\text { Baseline iron deficiency } \\
\text { sTfR }>28.1 \mathrm{nmol} / \mathrm{L} \\
n=573(26.8)\end{array}$ & $\begin{array}{l}\text { No baseline iron deficiency } \\
\text { sTfR } \leq 28.1 \mathrm{nmol} / \mathrm{L} \\
n=1568(73.2)\end{array}$ & $p$ value $^{\mathrm{a}}$ & $n=2141$ \\
\hline $\operatorname{Sex}, N(\%)$ & & & 0.29 & \\
\hline Women & $363(63.4)$ & $954(60.8)$ & & $1317(61.5)$ \\
\hline Men & $210(36.7)$ & $614(39.2)$ & & $824(38.5)$ \\
\hline Age, mean (SD), years & $75.6(4.7)$ & $74.7(4.3)$ & $<0.001$ & $74.9(4.5)$ \\
\hline Education, years & $12.1(4.4)$ & $12.9(4.2)$ & $<0.001$ & $12.7(4.3)$ \\
\hline BMI, mean (SD), $\mathrm{kg} / \mathrm{m}^{2}$ & $27.1(4.5)$ & $26.0(4.2)$ & $<0.001$ & $26.3(4.3)$ \\
\hline Alcohol, mean (SD), g/day & $7.7(11.1)$ & $9.3(11.9)$ & 0.008 & $8.9(11.7)$ \\
\hline Current smokers, $N(\%)$ & $14(2.4)$ & $111(7.1)$ & $<0.001$ & $125(5.8)$ \\
\hline Live alone, $N(\%)$ & $242(42.2)$ & $655(41.8)$ & 0.85 & $897(41.9)$ \\
\hline Physical activity, $N(\%)$ & & & 0.009 & \\
\hline None & $123(21.5)$ & 249 (15.9) & & $372(17.4)$ \\
\hline 1-2 times per week & $170(29.7)$ & $474(30.3)$ & & $644(30.1)$ \\
\hline$\geq 3$ times per week & $280(48.9)$ & $843(53.8)$ & & $1123(52.5)$ \\
\hline Frailty status ${ }^{\mathrm{b}}, N(\%)$ & & & 0.007 & \\
\hline Robust & $272(48.4)$ & $852(55.1)$ & & $1124(53.3)$ \\
\hline At least pre-frail & $290(51.6)$ & $695(44.9)$ & & $985(46.7)$ \\
\hline Polypharmacy ${ }^{\mathrm{c}}, N(\%)$ & $191(33.3)$ & $384(24.5)$ & $<0.001$ & $575(26.9)$ \\
\hline Iron supplementation, $N(\%)$ & $37(6.5)$ & $83(5.3)$ & 0.30 & $120(5.6)$ \\
\hline Number of comorbidities ${ }^{\mathrm{d}}$, mean (SD) & $2(1.5)$ & $1.6(1.4)$ & $<0.001$ & $1.7(1.4)$ \\
\hline Anemia $^{\mathrm{e}}, N(\%)$ & $63(11.0)$ & $77(4.9)$ & $<0.001$ & $140(6.5)$ \\
\hline hs-CRP, mean (SD), mg/L & $4.0(8.4)$ & $2.5(4.2)$ & $<0.001$ & $2.9(5.6)$ \\
\hline IL-6, mean (SD), ng/L & $4.7(9.3)$ & $3.5(5.9)$ & 0.003 & $3.8(6.9)$ \\
\hline Countries, $N(\%)$ & & & 0.02 & \\
\hline Austria & $55(9.6)$ & $143(9.1)$ & & $198(9.3)$ \\
\hline France & $73(12.7)$ & $226(14.1)$ & & $299(14.0)$ \\
\hline Germany & $92(16.1)$ & $254(16.2)$ & & $346(16.2)$ \\
\hline Portugal & $101(17.6)$ & $192(12.2)$ & & $293(13.7)$ \\
\hline Switzerland & $252(44.0)$ & $753(48.0)$ & & $1005(46.9)$ \\
\hline
\end{tabular}

$B M I$ Body Mass Index, sTfR soluble Transferrin Receptor, $h s$-CRP high-sensitivity C-Reactive Protein, $I L-6$ Interleukin-6

${ }^{a}$ Differences between iron-deficient and non-iron-deficient participants at baseline were assessed by an independent $t$ test for continuous variables and Chi-square test for categorical variables.

${ }^{\mathrm{b}}$ Frailty status was defined using the Fried Physical Frailty Phenotype which evaluates 5 criteria: fatigue (self-reported), unintentional weight loss (self-reported loss more than 5\% of total body weight), reduced physical activity (self-reported), slowness (impaired walking speed) and weakness (low grip strength). Participants are classified as at least pre-frail when one or more of the criteria are presented, and otherwise classified as robust.

${ }^{c}$ Polypharmacy was defined as the concomitant use of 5 or more medications.

${ }^{\mathrm{d}}$ Self-reported number of comorbidities was assessed by the Sangha questionnaire, range $0-13$.

${ }^{\mathrm{e}}$ Anemia was defined as hemoglobin $<130 \mathrm{~g} / \mathrm{L}$ for men and $<120 \mathrm{~g} / \mathrm{L}$ for women.

baseline and year 3 in male ID subjects, while there was no significant change in hs-CRP levels over time in both female subgroups (Online Resource 1). A significant interaction was also found between baseline ID and age groups $(P=0.01)$. In younger participants, IL-6 levels increased regardless the iron status, without any significant difference across all time points. In older subjects, ID was significantly associated with a greater increase in IL-6 levels over time (Online Resource 2). 
Table. 2 Changes from baseline in hs-CRP and IL-6 levels by baseline iron status

\begin{tabular}{|c|c|c|c|c|}
\hline & $\begin{array}{l}\text { Baseline iron deficiency } \\
\text { sTfR levels }>28.1 \mathrm{nmol} / \mathrm{L}\end{array}$ & $\begin{array}{l}\text { No baseline iron deficiency } \\
\text { sTfR levels } \leq 28.1 \mathrm{nmol} / \mathrm{L}\end{array}$ & $\begin{array}{l}\text { Mean difference in } \\
\text { change from baseline } \\
(95 \% \mathrm{CI})\end{array}$ & $\begin{array}{l}\mathrm{P} \text { value for mean difference } \\
\text { in change from baseline } \\
\text { between groups }{ }^{\text {a }}\end{array}$ \\
\hline & $n=573$ & $n=1568$ & & \\
\hline \multicolumn{5}{|l|}{ hs-CRP (mg/L) } \\
\hline $\begin{array}{l}\text { Unadjusted at baseline, } \\
\text { mean (SD) }\end{array}$ & $3.99(0.35)$ & $2.49(0.10)$ & $1.49(0.78$ to 2.21$)$ & $<0.001$ \\
\hline $\begin{array}{l}\text { Adjusted change at Year } 1 \\
(95 \% \mathrm{CI})\end{array}$ & $0.07(-0.37$ to 0.50$)$ & $-0.29(-0.54$ to -0.05$)$ & $0.36(0.15$ to 0.87$)$ & 0.16 \\
\hline $\begin{array}{l}\text { Adjusted change at Year } 2 \\
(95 \% \mathrm{CI})\end{array}$ & $0.19(-0.29$ to 0.68$)$ & $0.00(-0.35$ to 0.35$)$ & $0.19(-0.40$ to 0.79$)$ & 0.52 \\
\hline $\begin{array}{l}\text { Adjusted change at Year } 3 \\
(95 \% \mathrm{CI})\end{array}$ & $-0.26(-0.57$ to 0.05$)$ & $-0.26(-0.56$ to 0.04$)$ & $-0.01(-0.44$ to 0.43$)$ & 0.98 \\
\hline $\begin{array}{l}\text { Adjusted change across all } \\
\text { time points }(95 \% \mathrm{CI})\end{array}$ & $-0.00(-0.28$ to 0.28$)$ & $-0.18(-0.38$ to 0.01$)$ & $0.18(-0.16$ to 0.52$)$ & 0.29 \\
\hline \multicolumn{5}{|l|}{ IL-6 (ng/L) } \\
\hline $\begin{array}{l}\text { Unadjusted at baseline, } \\
\text { mean (SD) }\end{array}$ & $4.72(0.39)$ & $3.46(0.15)$ & $1.26(0.45$ to 2.07$)$ & 0.003 \\
\hline $\begin{array}{l}\text { Adjusted change at Year } 1 \\
(95 \% \mathrm{CI})\end{array}$ & $0.93(0.43$ to 1.43$)$ & $0.43(0.15$ to 0.70$)$ & $0.51(-0.09$ to 1.10$)$ & 0.09 \\
\hline $\begin{array}{l}\text { Adjusted change at Year } 2 \\
(95 \% \mathrm{CI})\end{array}$ & $0.98(0.50$ to 1.47$)$ & $0.70(0.41$ to 0.98$)$ & $0.29(-0.31$ to 0.89$)$ & 0.35 \\
\hline $\begin{array}{l}\text { Adjusted change at Year } 3 \\
(95 \% \mathrm{CI})\end{array}$ & $1.20(0.55$ to 1.85$)$ & $0.44(0.20$ to 0.69$)$ & $0.75(0.03$ to 1.48$)$ & 0.04 \\
\hline $\begin{array}{l}\text { Adjusted change across all } \\
\text { time points }(95 \% \mathrm{CI})\end{array}$ & $1.04(0.65$ to 1.43$)$ & $0.52(0.31$ to 0.73$)$ & $0.52(0.03$ to 1.00$)$ & 0.04 \\
\hline
\end{tabular}

a $p$ values correspond to the mean differences in biomarkers levels or changes in biomarker levels between iron-deficient and non-iron-deficient groups. Baseline levels are compared using a $t$ test. Yearly changes from baseline are compared by repeated measures linear regression with interaction terms between iron deficiency status and time. Overall differences across all time points are compared by repeated measures linear regression with a main effect for iron deficiency

Models are adjusted for treatment allocation, age, sex, center, body mass index over the follow-up, alcohol consumption, tobacco consumption, polypharmacy, number of comorbidities, frailty status (pre-frailty), frequency of physical activity, yearly incidence rate of infections, and baseline level of the outcome

sTfR soluble Transferrin Receptor

Values in bold indicate significant $\mathrm{P}$ values

\section{Association between yearly-assessed ID and inflammatory biomarkers}

Participants with ID at any yearly follow-up time point had $1.59 \mathrm{mg} / \mathrm{L}$ higher concentration of hs-CRP at baseline (unadjusted, 95\% CI 0.89-2.29, $P<0.001$ ) (Table 3). Across all yearly follow-ups, there was a significant increase in hs-CRP levels among subjects with ID at a particular follow-up time point $(1.07 \mathrm{mg} / \mathrm{L})$, while there was a significant decrease in hs-CRP levels in participants who did not have ID at these time points $(-0.55 \mathrm{mg} / \mathrm{L})$. The presence of ID at a yearly follow-up time point was associated with a statistically significant greater increase in hs-CRP levels (MD: $1.62 \mathrm{mg} / \mathrm{L}$, 95\% CI 0.98-2.26, $P<0.001$ ) (Fig. 1c).

At baseline, IL-6 levels were significantly higher in participants who had ID at any yearly follow-up time point (unadjusted MD: 1.19 ng/L, 95\% CI 0.52-1.86, $P<0.001$ ).
Over time, we observed a significant increase in IL-6 levels among both participants with ID (1.65 ng/L) and without ID $(0.32 \mathrm{ng} / \mathrm{L})$. The presence of ID at any yearly time point over the follow-up was associated with a greater increase in IL-6 levels (MD: $1.33 \mathrm{mg} / \mathrm{L}, 95 \%$ CI $0.87-1.79, P<0.001$ ) (Fig. 1d).

We did not find any significant interaction between ID at any yearly follow-up time point and anemic status $(P=0.24$ and $P=0.46$ in hs-CRP and IL-6 models, respectively), suggesting that the results are independent of the presence of anemia. Results were similar for the interaction between ID at any yearly time point and sex $(P=0.25$ in hs-CRP model and $P=0.72$ in IL-6 model) or age groups $(P=0.59$ in hs-CRP model and $P=0.32$ in IL-6 model). 
A Adjusted mean $(95 \% \mathrm{Cl})$ change from baseline in hs-CRP levels over 3 years by baseline iron status

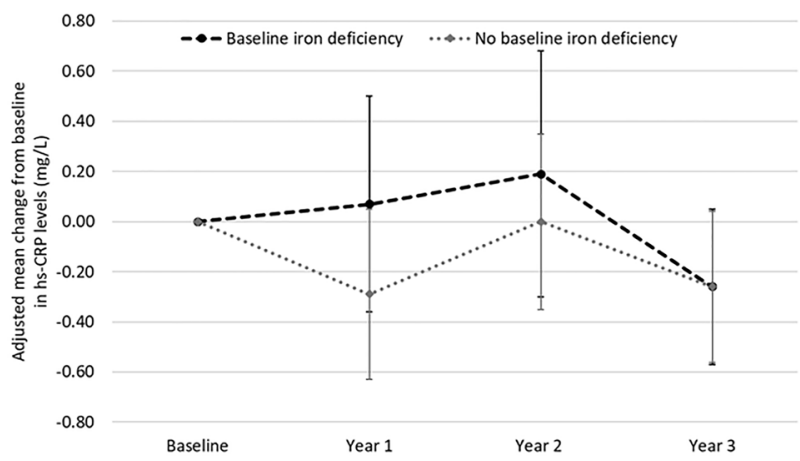

B

Adjusted mean $(95 \% \mathrm{CI})$ change from baseline in IL- 6 levels over 3 years by baseline iron status

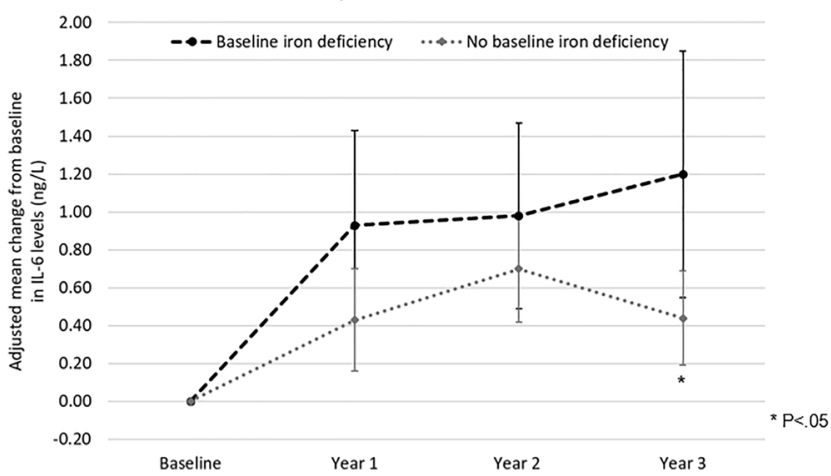

Fig 1 Changes in inflammatory biomarkers levels over time. The adjusted mean change from baseline over three years is shown for (a) hs-CRP levels by baseline iron status, b IL-6 levels by baseline iron

\section{Sensitivity analysis}

\section{Association between baseline ID defined with ferritin levels and transferrin-ferritin index and inflammatory biomarkers}

Over 3 years, no statistically significant difference over time in hs-CRP levels was found between ID and non-ID groups, when ID was defined by both $<45 \mu \mathrm{g} / \mathrm{L}$ and $<30 \mu \mathrm{g} / \mathrm{L}$ ferritin levels (Online Resource 3). IL-6 levels significantly increased in all subjects, without any significant difference between the 2 groups over time, regardless of the ferritin cut-off used.

When defining ID with transferrin-ferritin index, ID was associated with a greater increase in hs-CRP and IL-6 concentrations, across all time points (Online Resource 3 ).

\section{Association between ID defined with ferritin levels and transferrin-ferritin index over the follow-up and inflammatory biomarkers}

Regardless of the cut-off applied for ferritin levels, the presence of ID at any yearly time point was associated with a

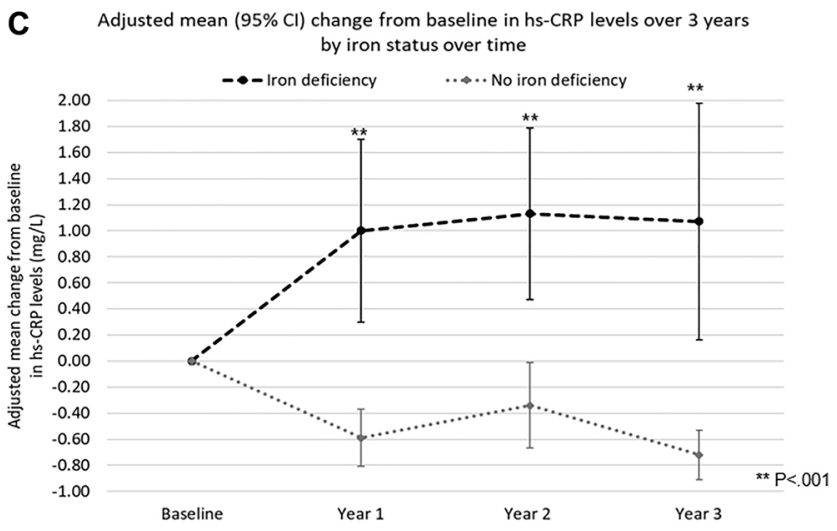

D Adjusted mean $(95 \% \mathrm{Cl})$ change from baseline in IL-6 levels over 3 years by iron status over time

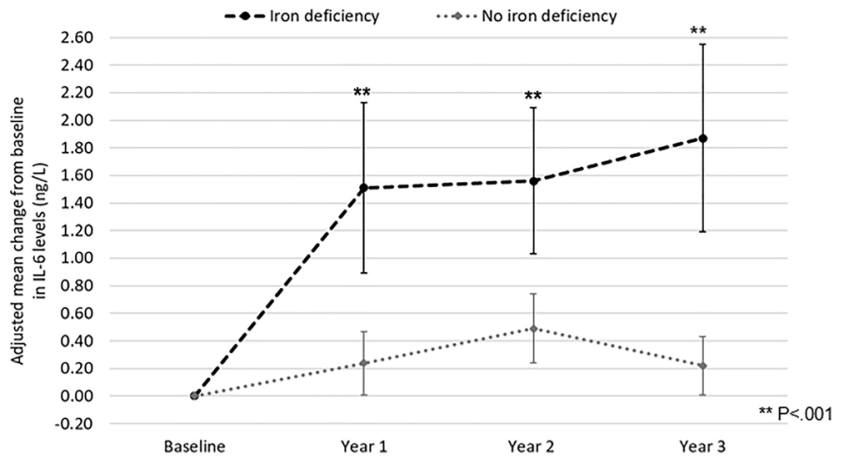

status, c hs-CRP levels by iron status at each yearly time point over the follow-up, and d IL-6 levels by iron status at each yearly time point over the follow-up

decrease in hs-CRP levels across all time points (Online Resource 4). There was no significant difference in IL-6 levels between participants with ID at a particular time over the follow-up and those without. When defined by transferrin-ferritin index $>1.5$, the presence of ID at any yearly time point over the follow-up was associated with a greater increase in IL-6 across all time points (Online Resource 4).

\section{Association between recurrent ID and inflammatory biomarkers}

Across all time points, the presence of recurrent iron deficiency was associated with statistically significant greater increases in hs-CRP and IL-6 levels (Online Resource 5).

\section{Exclusion of participants with baseline liver, kidney disease, and incident invasive cancers}

When excluding participants with baseline liver, kidney disease, and incident invasive cancers, results were consistent with those observed in the main analysis (Online Resource $6)$. 
Table 3 Changes from baseline in hs-CRP and IL-6 levels by yearly-assessed iron status

\begin{tabular}{|c|c|c|c|c|}
\hline & $\begin{array}{l}\text { Iron deficiency at any } \\
\text { yearly follow-up time point } \\
\text { sTfR levels }>28.1 \mathrm{nmol} / \mathrm{L}\end{array}$ & $\begin{array}{l}\text { No iron deficiency at any yearly } \\
\text { follow-up time point } \\
\text { sTfR levels } \leq 28.1 \mathrm{nmol} / \mathrm{L}\end{array}$ & $\begin{array}{l}\text { Mean difference in } \\
\text { change from base- } \\
\text { line }(95 \% \mathrm{CI})\end{array}$ & $\begin{array}{l}P \text { value for mean } \\
\text { difference in change } \\
\text { from baseline between } \\
\text { groups }^{\text {a }}\end{array}$ \\
\hline \multicolumn{5}{|l|}{ hs-CRP (mg/L) } \\
\hline $\begin{array}{l}\text { Unadjusted at baseline, } \\
\text { mean (SD) }\end{array}$ & $4.05(0.34)$ & $2.47(0.11)$ & $1.59(0.89$ to 2.29$)$ & $<0.001$ \\
\hline $\begin{array}{l}\text { Adjusted change at Year } 1 \\
(95 \% \mathrm{CI})\end{array}$ & $1.00(0.30$ to 1.70$)[n=481]$ & - $0.59(-\mathbf{0 . 8 1}$ to $-\mathbf{0 . 3 7})[n=1419]$ & $1.59(0.82$ to 2.37$)$ & $<0.001$ \\
\hline $\begin{array}{l}\text { Adjusted change at Year } 2 \\
\quad(95 \% \mathrm{CI})\end{array}$ & $1.13(0.47$ to 1.79$)[n=485]$ & $-0.34(-0.67$ to -0.01$)[n=1346]$ & $1.47(0.70$ to 2.24$)$ & $<0.001$ \\
\hline $\begin{array}{l}\text { Adjusted change at Year } 3 \\
(95 \% \mathrm{CI})\end{array}$ & $1.07(0.17$ to 1.98$)[n=462]$ & $-0.72(-0.90$ to $-\mathbf{0 . 5 3})[n=1367]$ & $1.80(0.83$ to 2.77$)$ & $<0.001$ \\
\hline $\begin{array}{l}\text { Adjusted change across all } \\
\text { time points }(95 \% \mathrm{CI})\end{array}$ & $1.07(0.50$ to 1.63$)$ & $-0.55(-0.72$ to -0.38$)$ & $1.62(0.98$ to 2.26$)$ & $<0.001$ \\
\hline \multicolumn{5}{|l|}{ IL-6 (ng/L) } \\
\hline $\begin{array}{l}\text { Unadjusted at baseline, } \\
\text { mean (SD) }\end{array}$ & $4.66(0.33)$ & $3.48(0.15)$ & $1.19(0.52$ to 1.86$)$ & $<0.001$ \\
\hline $\begin{array}{l}\text { Adjusted change at Year } 1 \\
(95 \% \mathrm{CI})\end{array}$ & $1.51(0.88$ to 2.13$)[n=481]$ & $0.24(0.01-0.47)[n=1419]$ & $1.27(0.60$ to 1.94$)$ & $<0.001$ \\
\hline $\begin{array}{l}\text { Adjusted change at Year } 2 \\
\quad(95 \% \mathrm{CI})\end{array}$ & $1.56(1.04$ to 2.09$)[n=485]$ & $0.49(0.24-0.74)[n=1346]$ & $1.07(0.48$ to 1.67$)$ & $<0.001$ \\
\hline $\begin{array}{l}\text { Adjusted change at Year } 3 \\
\quad(95 \% \mathrm{CI})\end{array}$ & $1.87(1.18$ to 2.55$)[n=462]$ & $\mathbf{0 . 2 2}(\mathbf{0 . 0 1 - 0 . 4 3 )}[n=1367]$ & $1.65(0.92$ to 2.37$)$ & $<0.001$ \\
\hline $\begin{array}{l}\text { Adjusted change across all } \\
\text { time points }(95 \% \mathrm{CI})\end{array}$ & $1.65(1.23$ to 2.06$)$ & $0.32(0.14-0.49)$ & $1.33(0.87$ to 1.79$)$ & $<0.001$ \\
\hline
\end{tabular}

${ }^{a} p$ values correspond to the mean differences in biomarkers levels or changes in biomarker levels between iron-deficient and non-iron-deficient groups. Baseline levels are compared using a $t$ test. Yearly changes from baseline are compared by repeated measures linear regression with interaction terms between iron deficiency status and time. Overall differences across all time points are compared by repeated measures linear regression with a main effect for iron deficiency

Models are adjusted for treatment allocation, age, sex, center, body mass index over the follow-up, alcohol consumption, tobacco consumption, polypharmacy, number of comorbidities, frailty status (pre-frailty), frequency of physical activity, yearly incidence rate of infections, baseline iron status and baseline level of the outcome

Numbers between squared brackets indicate the number of iron-deficient and non-iron-deficient participants at each yearly time point

sTfR soluble Transferrin Receptor

Values in bold indicate significant $P$ values

\section{Discussion}

To the best of our knowledge, the present study is the first to investigate the longitudinal association between ID and lowgrade chronic inflammation in a large cohort of relatively healthy European community-dwelling older adults.

At baseline, ID defined by sTfR levels was cross-sectionally associated with higher levels of hs-CRP and IL-6. Across all time points, the change from baseline in hs-CRP levels did not differ according to the iron status, while a significantly greater increase in IL-6 levels was observed in participants with ID at baseline. Participants with ID at any yearly time point over the follow-up had higher levels of inflammatory biomarkers at baseline. Similarly, we observed significant increases in hs-CRP levels and in IL-6 levels at follow-up time points when participants had ID at that time point.

Our results are partly consistent with those of a recent cross-sectional study. [20] Askar et al. found that CRP and IL-6 levels significantly increased in 20 middle-aged women with ID anemia (defined by ferritin $<15 \mu \mathrm{g} / \mathrm{L}$ and hemoglobin level of $<11.5 \mathrm{~g} / \mathrm{dL}$ ), when compared to their disease-free counterparts. Nevertheless, in our large study population of older adults, we did not find any statistically significant interaction between ID and baseline anemia, suggesting the results herein are independent of anemic status.

While the presence of ID at any yearly time point over the follow-up was associated with high levels of inflammatory biomarkers, we found opposite trends in non-ID participants. We observed a significant decrease in hs-CRP levels while IL-6 significantly increased over time. These different trends 
in inflammatory biomarkers levels were also observed in another large 3-year observational study including 4979 older adults, regardless of the iron status. [47] Since IL-6 is known to induce the production of CRP, this lack of timely overlap between IL- 6 and hs-CRP levels could be explained by the intervention of hepcidin [48] and other cytokines not measured in the present study (e.g., IL-1, IL-17). [49] More recently, a review described that elevated IL-6 levels may also indicate protection, preservation, and/or repair of somatic tissue in an aging organism. [5].

Additionally, we found that baseline ID was associated with a significantly greater increase in IL-6 levels across all time points. These results may suggest ID as a promotor of low-grade chronic inflammation measured with IL-6. Given limited current scientific evidence on ID predicting inflammation and the observational nature of our study, our results are hypothesis generating. Thus, this work constitutes a first step to further investigate the role of ID and other regulators of iron on inflammation homeostasis such as hepcidin and their implications in healthy aging.

Furthermore, there is currently no consensus to define ID in older adults. We conducted sensitivity analyses to consider the most used definitions in clinical practice. Compared to our main analysis, contradictory results were obtained when using ferritin levels to define ID. Since ferritin is influenced by inflammatory conditions due to its additional function as acute-phase protein [50], our results confirmed that it might be less suitable to investigate ID in older adults. [51] Another point that has to be mentioned is the absence of evidence-based clinical thresholds to draw conclusions about the clinical relevance of increases or decreases in IL- 6 and hs-CRP levels in our study population. For hs-CRP levels, a previous longitudinal large study used a cut-off of more than $3 \mathrm{mg} / \mathrm{L}$ to define the presence of systemic inflammation, since mildly elevated hs-CRP levels are particularly common in older adults. [52] When using this cut-off, it confirmed that our participants with ID at baseline or at any yearly follow-up time point presented a systemic inflammation since their hs-CRP levels were continually over $3 \mathrm{mg} / \mathrm{L}$, while not in non-iron-deficient participants. Concerning IL-6 levels, current literature stated that IL-6 serum levels higher than $2 \mathrm{ng} / \mathrm{L}$ can be considered to define chronic inflammation in an older adult population. [53, 54] In the DO-HEALTH participants, IL-6 levels were higher than $2 \mathrm{ng} / \mathrm{L}$ at baseline and over time, regardless of the iron status. Nevertheless, the presence of ID over the follow-up was associated with higher increases of inflammatory biomarkers over time, compounding pre-existing chronic inflammation. Describing and interpreting the variations in inflammatory biomarkers over time could be of importance, especially when considering the concepts of aging and inflammaging. As evidenced by current literature, permanently elevated levels of IL- 6 and CRP have been suggested as promoters of accelerated aging [10], frailty, decline in cognitive functions, age-related chronic disease, and a higher risk of mortality. [38] Hence, screening older adults for ID may be relevant for healthy aging, and preventing chronic diseases, and loss of autonomy in an increasingly, aging population. Once ID has been identified, education on dietary sources of iron as well as substances inhibiting iron absorption should be provided. [30] Alternatively, iron supplementation might be discussed. In octogenarians, low-dose supplementation of $15 \mathrm{mg}$ of oral iron per day was reported to be safe and effective [55].

\section{Strengths and limitations}

Our study took advantage of data collected in the DOHEALTH trial, the largest European study on aging that included and followed 2157 community-dwelling older adults over 3 years. We assessed long-term chronic inflammation with annually repeated measurements of two reliable inflammatory biomarkers, broadly used in clinical practice. Besides, we extensively investigated the influence of ID on inflammatory biomarkers levels using four different definitions. We also strengthened the validity of our results in adjusting on a wide range of potential confounders and in performing several sensitivity analyses. However, a few limitations need consideration. Due to the observational nature of our study and despite adjustment for several relevant sociodemographic and clinical factors, we cannot exclude the possibility that the observed associations between ID and high levels of inflammatory biomarkers may be explained in part by residual confounding.

\section{Conclusion}

Our results suggest that ID may play a relevant role in chronic low-grade inflammation measured by hs-CRP and IL-6 levels among relatively healthy older adults.

Supplementary Information The online version contains supplementary material available at https://doi.org/10.1007/s40520-021-01955-3.

Acknowledgements We thank all the members of the DO-HEALTH Research Group, and we are grateful to the patients for their participation in, and commitment to, this study.

Authors' contributions MW and FS: contributed equally as co-first authors, they performed the literature survey, the drafting of the article and the statistical analyses with input by AS, LA, CdGRCM, EJO and HBF. HBF: is the PI of DO-HEALTH and is the PI of this study, with input by AE, EJO, DRS, and DJS. All authors contributed to the acquisition, analysis or interpretation of data and they all have read and approved the manuscript.

Funding Open Access funding provided by Universität Zürich. This analysis of the DO-HEALTH data set was funded by an independent 
and investigator-initiated grant funded by Vifor Pharma. The DOHEALTH study was funded by the Seventh Research Framework Program of the European Commission (Grant Agreement $n^{\circ} 278588$ ), and within this framework, also by the University of Zurich (Chair for Geriatric Medicine and Aging Research), DNP, Roche, NESTEC, Pfizer and Streuli. The funding/supporting organizations had no role in the design and conduct of DO-HEALTH, including collection, management, analysis, and interpretation of the data, as well as preparation, review, or approval of the manuscript, or decision to submit the manuscript for publication.

Data availability In a first step, no data will be made available to researchers external to DO-HEALTH Research Group to allow primary researchers to fully exploit the dataset. The data will be shared in a second step according to a controlled access system.

\section{Declarations}

Conflict of interest LA is currently an employee of MSD, Switzerland. DRS reports personal fees from Danube University of Krems, US Department of Defense, European Society of Anesthesiology, Korean Society for Patient Blood Management, Korean Society of Anesthesiologists, Network for the Advancement of Patient Blood Management, Haemostasis and Thrombosis, Bayer AG, Zürich, B. Braun Melsungen AG, Boehringer Ingelheim GmbH, Bristol-Myers-Squibb, CSL Behring GmbH, Celgene International II Sàrl, Daiichi Sankyo AG, Haemonetics, Instrumentation Laboratory (Werfen), LFB Biomédicaments, Merck Sharp \& Dohme, PAION Deutschland GmbH, Pharmacosmos A/S, Pfizer AG, Pierre Fabre Pharma, Portola Schweiz $\mathrm{GmbH}$, Roche Diagnostics International Ltd, Sarstedt AG \& Co., Shire Switzerland GmbH, Tem International GmbH, Vifor Pharma, Vifor (International) AG, Zuellig Pharma Holdings. DRS's academic department is receiving grant support from the Swiss National Science Foundation, the Swiss Society of Anesthesiology and Reanimation (SGAR), the Swiss Foundation for Anesthesia Research, Vifor SA and Vifor (International) AG. DRS is co-chair of the ABC-Trauma Faculty, sponsored by unrestricted educational grants from Novo Nordisk Health Care AG, CSL Behring GmbH, LFB Biomédicaments, and Octapharma AG. EJO reports grants from Zurich University, during the conduct of the study. As part of the DO-HEALTH independent and investigator-initiated clinical trial, HABF reports as the PI of the DOHEALTH trial, grants from European Commission, from University of Zurich, from NESTEC, from PFIZER Consumer Healthcare, from Streuli Pharma, plus nonfinancial support from DSM Nutritional Products and nonfinancial support from Roche Diagnostics. Further, Prof. Bischoff-Ferrari reports speaker fees from Wild, Pfizer, Vifor, Mylan, Roche Diagnostics, and independent and investigator-initiated grants from Pfizer and from Vifor. All other authors declare no competing interests.

Ethics approval statement The Cantonal Ethical Committee of the Canton of Zurich approved this ancillary analysis (BASEC $\mathrm{N}^{\circ} 2018$ 01755).

Informed consent Informed consent was obtained from all individual participants included in the study.

Open Access This article is licensed under a Creative Commons Attribution 4.0 International License, which permits use, sharing, adaptation, distribution and reproduction in any medium or format, as long as you give appropriate credit to the original author(s) and the source, provide a link to the Creative Commons licence, and indicate if changes were made. The images or other third party material in this article are included in the article's Creative Commons licence, unless indicated otherwise in a credit line to the material. If material is not included in the article's Creative Commons licence and your intended use is not permitted by statutory regulation or exceeds the permitted use, you will need to obtain permission directly from the copyright holder. To view a copy of this licence, visit http://creativecommons.org/licenses/by/4.0/.

\section{References}

1. Vetrano DL, Zucchelli A, Marconi E et al (2020) Predictors of iron-deficiency anemia in primary care older adults: a real-world European multi-country longitudinal study. Aging Clin Exp Res 32:2211-2216. https://doi.org/10.1007/s40520-019-01454-6

2. Pasricha SR, Drakesmith H, Black J et al (2013) Control of iron deficiency anemia in low- and middle-income countries. Blood 121:2607-2617. https://doi.org/10.1182/blood-2012-09-453522

3. Kassebaum NJ (2016) The global burden of Anemia. Hematol Oncol Clin North Am 30:247-308. https://doi.org/10.1016/j.hoc. 2015.11.002

4. Jonker FAM, van Hensbroek MB (2014) Anaemia, iron deficiency and susceptibility to infections. J Infect 69:S23-S27. https://doi.org/10.1016/j.jinf.2014.08.007

5. Del Giudice M, Gangestad SW (2018) Rethinking IL-6 and CRP: Why they are more than inflammatory biomarkers, and why it matters. Brain Behav Immun 70:61-75. https://doi.org/10.1016/j. bbi.2018.02.013

6. Nemeth E, Rivera S, Gabayan V et al (2004) IL-6 mediates hypoferremia of inflammation by inducing the synthesis of the iron regulatory hormone hepcidin. J Clin Investig 113:1271-1276. https://doi.org/10.1172/JCI20945

7. Cappellini MD, Comin-Colet J, de Francisco A et al (2017) Iron deficiency across chronic inflammatory conditions: International expert opinion on definition, diagnosis, and management. Am J Hematol 92:1068-1078. https://doi.org/10.1002/ajh.24820

8. Nairz M, Theurl I, Wolf D et al (2016) Iron deficiency or anemia of inflammation? : Differential diagnosis and mechanisms of anemia of inflammation. Wien Med Wochenschr 166:411-423. https://doi.org/10.1007/s10354-016-0505-7

9. Milan-Mattos JC, Anibal FF, Perseguini NM et al (2019) Effects of natural aging and gender on pro-inflammatory markers. Braz J Med Biol Res 52:e8392. https://doi.org/10.1590/1414-431x2 0198392

10. Tsuboi A, Watanabe M, Kazumi T et al (2013) Association of low serum iron levels with low-grade inflammation and hyperadiponectinemia in community-living elderly women. $\mathrm{J}$ Atheroscler Thromb 20:670-677. https://doi.org/10.5551/jat.16071

11. Ferrucci L, Fabbri E (2018) Inflammageing: chronic inflammation in ageing, cardiovascular disease, and frailty. Nat Rev Cardiol 15:505-522. https://doi.org/10.1038/s41569-018-0064-2

12. De Franceschi L, Iolascon A, Taher A et al (2017) Clinical management of iron deficiency anemia in adults: Systemic review on advances in diagnosis and treatment. Eur J Intern Med 42:16-23. https://doi.org/10.1016/j.ejim.2017.04.018

13. Velissaris D, Pantzaris N, Koniari I et al (2017) C-reactive protein and frailty in the elderly: a literature review. J Clin Med Res 9:461-465. https://doi.org/10.14740/jocmr2959w

14. Rohrig G (2016) Anemia in the frail, elderly patient. Clin Interv Aging 11:319-326. https://doi.org/10.2147/cia.S90727

15. Li Z-H, Zhong W-F, Lv Y-B et al (2019) Associations of plasma high-sensitivity $\mathrm{C}$-reactive protein concentrations with all-cause and cause-specific mortality among middle-aged and elderly individuals. Immun Ageing 16:28. https://doi.org/10.1186/ s12979-019-0168-5

16. Chen C, Liu Y, Cao Z et al (2019) Combined associations of hs-CRP and cognitive function with all-cause mortality among 
oldest-old adults in Chinese longevity areas: a prospective cohort study. Immun Ageing 16:30. https://doi.org/10.1186/ s12979-019-0170-y

17. Ferrando-Martínez S, Romero-Sánchez MC, Solana R et al (2013) Thymic function failure and C-reactive protein levels are independent predictors of all-cause mortality in healthy elderly humans. Age 35:251-259. https://doi.org/10.1007/ s11357-011-9341-2

18. Giovannini S, Onder G, Liperoti R et al (2011) Interleukin-6, $\mathrm{C}$-reactive protein, and tumor necrosis factor-alpha as predictors of mortality in frail, community-living elderly individuals. J Am Geriatr Soc 59:1679-1685. https://doi.org/10.1111/j.1532-5415. 2011.03570.x

19. Robalo Nunes A, Fonseca C, Marques F, Belo A, Brilhante D, Cortez J (2017) Prevalence of anemia and iron deficiency in older Portuguese adults: An EMPIRE substudy. Geriatr Gerontol Int. 17:1814-1822. https://doi.org/10.1111/ggi.12966

20. Askar S, Deveboynu SN, Er H et al (2019) Changes in pro-inflammatory cytokines and antimicrobial proteins in elderly women with iron deficiency anemia. Pak J Med Sci 35:298-301. https:// doi.org/10.12669/pjms.35.2.520

21. Fairweather-Tait SJ, Wawer AA, Gillings R et al (2014) Iron status in the elderly. Mech Ageing Dev 136-137:22-28. https://doi.org/ 10.1016/j.mad.2013.11.005

22. Busti F, Campostrini N, Martinelli N et al (2014) Iron deficiency in the elderly population, revisited in the hepcidin era. Front Pharmacol 5:83

23. Bischoff-Ferrari HA, Molino C, Rival S et al (2020) DOHEALTH: Vitamin D3 - Omega3 - Home exercise - Healthy aging and longevity trial - Design of a multinational clinical trial on healthy aging among European seniors. Contemp Clin Trials. https://doi.org/10.1016/j.cct.2020.106124

24. Fullenbach C, Stein P, Glaser P et al (2020) Screening for iron deficiency in surgical patients based on noninvasive zinc protoporphyrin measurements. Transfusion 60:62-72. https://doi.org/ $10.1111 /$ trf. 15577

25. Joosten E, Van Loon R, Billen J et al (2002) Serum transferrin receptor in the evaluation of the iron status in elderly hospitalized patients with anemia. Am J Hematol 69:1-6. https://doi.org/10. 1002/ajh.10014

26. Choi CW, Cho WR, Park KH et al (2005) The cutoff value of serum ferritin for the diagnosis of iron deficiency in communityresiding older persons. Ann Hematol 84:358-361. https://doi.org/ 10.1007/s00277-005-1033-5

27. López-Sierra M, Calderón S, Gómez J et al (2012) Prevalence of anaemia and evaluation of transferrin receptor (sTfR) in the diagnosis of iron deficiency in the hospitalized elderly patients: anaemia clinical studies in chile. Anemia 2012:646201. https:// doi.org/10.1155/2012/646201

28. Wang W, Knovich MA, Coffman LG et al (2010) Serum ferritin: Past, present and future. Biochim Biophys Acta 1800:760-769. https://doi.org/10.1016/j.bbagen.2010.03.011

29. Guyatt GH, Patterson C, Ali M et al (1990) Diagnosis of irondeficiency anemia in the elderly. Am J Med 88:205-209. https:// doi.org/10.1016/0002-9343(90)90143-2

30. Clenin GE (2017) The treatment of iron deficiency without anaemia (in otherwise healthy persons). Swiss Med Wkly 147:w14434. https://doi.org/10.4414/smw.2017.14434

31. Yu D, Huo J, Xie L et al (2013) Meta-analysis of studies on cut-off value of serum ferritin for identifying iron deficiency. Wei Sheng Yan Jiu 42:228-235

32. Rimon E, Levy S, Sapir A et al (2002) Diagnosis of iron deficiency anemia in the elderly by transferrin receptor-ferritin index. Arch Intern Med 162:445-449. https://doi.org/10.1001/archinte. 162.4.445
33. WHO (2011) Haemoglobin concentrations for the diagnosis of anaemia and assessment of severity. Geneva. https://apps.who. int/iris/handle/10665/85839

34. Chocano-Bedoya PO, Bischoff-Ferrari HA; DO-HEALTH (2019) Vitamin D3-Omega-3-Home Exercise-Healthy Aging and Longevity Trial-Dietary Patterns in Five European Countries. In: Weaver CM, Bischoff-Ferrari H, Daly RM et al (eds) Nutritional Influences on Bone Health: 10th International Symposium. Springer International Publishing, pp 3-10

35. Sangha O, Stucki G, Liang MH et al (2003) The Self-Administered Comorbidity Questionnaire: a new method to assess comorbidity for clinical and health services research. Arthritis Rheum 49:156-163. https://doi.org/10.1002/art.10993

36. Fried LP, Tangen CM, Walston J et al (2001) Frailty in older adults: evidence for a phenotype. J Gerontol A Biol Sci Med Sci 56:M146-M156. https://doi.org/10.1093/gerona/56.3.m146

37. Wolf AM, Hunter DJ, Colditz GA et al (1994) Reproducibility and validity of a self-administered physical activity questionnaire. Int J Epidemiol 23:991-999. https://doi.org/10.1093/ije/23.5.991

38. Michaud M, Balardy L, Moulis G et al (2013) Proinflammatory cytokines, aging, and age-related diseases. J Am Med Dir Assoc 14:877-882. https://doi.org/10.1016/j.jamda.2013.05.009

39. Wang JL, Shaw NS (2005) Iron status of the Taiwanese elderly: the prevalence of iron deficiency and elevated iron stores. Asia Pac J Clin Nutr 14:278-284

40. Seitz HK, Bataller R, Cortez-Pinto H et al (2018) Alcoholic liver disease. Nat Rev Dis Primers 4:16. https://doi.org/10.1038/ s41572-018-0014-7

41. Khan NA, Lawyer G, McDonough S et al (2020) Systemic biomarkers of inflammation, oxidative stress and tissue injury and repair among waterpipe, cigarette and dual tobacco smokers. Tob Control 29:s102-s109. https://doi.org/10.1136/tobaccocon trol-2019-054958

42. WHO (2019) C-reactive protein concentrations as a marker of inflammation or infection for interpreting biomarkers of micronutrient status. Geneva

43. Gkamprela E, Deutsch M, Pectasides D (2017) Iron deficiency anemia in chronic liver disease: etiopathogenesis, diagnosis and treatment. Ann Gastroenterol 30:405-413. https://doi.org/10. 20524/aog.2017.0152

44. Stein J, Connor S, Virgin G et al (2016) Anemia and iron deficiency in gastrointestinal and liver conditions. World J Gastroenterol 22:7908-7925. https://doi.org/10.3748/wjg.v22.i35.7908

45. Batchelor EK, Kapitsinou P, Pergola PE et al (2020) Iron Deficiency in chronic kidney disease: updates on pathophysiology, diagnosis, and treatment. J Am Soc Nephrol 31:456. https://doi. org/10.1681/ASN.2019020213

46. Gafter-Gvili A, Schechter A, Rozen-Zvi B (2019) Iron deficiency anemia in chronic kidney disease. Acta Haematol 142:44-50. https://doi.org/10.1159/000496492

47. Puzianowska-Kuźnicka M, Owczarz M, Wieczorowska-Tobis K et al (2016) Interleukin-6 and C-reactive protein, successful aging, and mortality: the PolSenior study. Immun Ageing 13:21-21. https://doi.org/10.1186/s12979-016-0076-x

48. Wrighting DM, Andrews NC (2006) Interleukin-6 induces hepcidin expression through STAT3. Blood 108:3204-3209. https:// doi.org/10.1182/blood-2006-06-027631

49. Eklund CM (2009) Proinflammatory cytokines in CRP baseline regulation. Adv Clin Chem 48:111-136. https://doi.org/10.1016/ s0065-2423(09)48005-3

50. Thachil J (2016) The beneficial effect of acute phase increase in serum ferritin. Eur J Intern Med 35:e16-e17. https://doi.org/10. 1016/j.ejim.2016.07.020

51. Cankurtaran M, Yavuz BB, Halil M et al (2012) Increased ferritin levels could reflect ongoing aging-associated inflammation and 
may obscure underlying iron deficiency in the geriatric population. European Geriatric Medicine 3:277-280. https://doi.org/10. 1016/j.eurger.2012.06.005

52. Lassale C, Batty GD, Steptoe A et al (2019) Association of 10-year C-reactive protein trajectories with markers of healthy aging: findings from the english longitudinal study of aging. $\mathrm{J}$ Gerontol A Biol Sci Med Sci 74:195-203. https://doi.org/10.1093/ gerona/gly028

53. Wyczalkowska-Tomasik A, Czarkowska-Paczek B, Zielenkiewicz $M$ et al (2016) Inflammatory markers change with age, but do not fall beyond reported normal ranges. Arch Immunol Ther Exp (Warsz) 64:249-254. https://doi.org/10.1007/s00005-015-0357-7
54. Akbaraly TN, Hamer M, Ferrie JE et al (2013) Chronic inflammation as a determinant of future aging phenotypes. CMAJ 185:E763-E770. https://doi.org/10.1503/cmaj.122072

55. Rimon E, Kagansky N, Kagansky M et al (2005) Are we giving too much iron? Low-dose iron therapy is effective in octogenarians. Am J Med 118:1142-1147. https://doi.org/10.1016/j.amjmed. 2005.01.065

Publisher's Note Springer Nature remains neutral with regard to jurisdictional claims in published maps and institutional affiliations. 